\title{
ENTREVISTA COM ERIK SWYNGEDOUW
}

\author{
César Augusto Ferrari Martinez ${ }^{1}$
}

\begin{abstract}
Resumo: Erik Swyngedouw é um geógrafo e ecologista político belga radicado no Reino Unido, onde é Professor de Geografia Política e Econômica na Escola de Meio Ambiente, Educação e Desenvolvimento da Universidade de Manchester. Com formação ambiental como engenheiro agrônomo e doutorado em geografia crítica, Swyngedouw é um dos autoreschave no entendimento dos usos da natureza como artefato de poder na produção do espaço pela modernidade. Sua obra inclui estudos sobre escala, discursos sobre a natureza, controle de redes hídricas, contextos de pós-democracia - todos pautados por densa análise crítica do processo de globalização. Recentemente, publicou Liquid Power, no qual analisa o papel do controle sobre as redes de água na produção do espaço espanhol pelo governo franquista. Esta entrevista se deu em inglês e pela ocasião da participação do Professor Swyngedouw na Conferência "Knowledge / Culture / Ecologies" em Santiago do Chile no mês de novembro de 2017, sendo traduzida por mim ao Português.
\end{abstract}

Palavras-chave: Escala; Marxismo; Globalização; Movimentos Sociais.

\section{INTERVIEW WITH ERIK SWYNGEDOUW}

\begin{abstract}
Erik Swyngedouw is a geographer and political ecologist who has been working in United Kingdom, where he is Professor of Political and Economic Geography at School of Environment, Education and Development of the University of Manchester. With environmental background and a $\mathrm{PhD}$ in critical geography, Swyngedouw is a key author in understanding the uses of nature as power dispositive in the production of space by modernity. His work covers studies on scale, nature discourses, water controlling, postdemocracy contexts - all guided by dense critical analysis of globalization process. He recently published Liquid Power, in which he analyzes the role of water controlling over the production of Spanish space by francoist government. This interview was conducted in English on the occasion of Professor Swyngedouw's participation in the "Knowledge / Culture / Ecologies" Conference in Santiago de Chile in November 2017, being translated by me to Portuguese.
\end{abstract}

Keywords: Scale; Marxism; Globalization; Social Movements.

\footnotetext{
${ }^{1}$ Professor no Departamento de Geografia da Universidade Federal de Pelotas. Licenciado e Mestre em Geografia (UFRGS), Doutor (c) em Educação (Pontificia Universidad Católica de Chile).
} 


\section{ENTREVISTA CON ERIK SWYNGEDOUW}

Resumen: Erik Swyngedouw es un geógrafo y ecologista político belga radicado en Reino Unido, donde es Profesor de Geografía Política y Económica en la Escuela de Medioambiente, Educación y Desarrollo de la Universidad de Manchester. De formación ambiental como ingeniero agrónomo y con doctorado en geografía crítica, Swyngedouw es uno de los autores clave en el entendimiento de los usos de la naturaleza como artefacto de poder en la producción de espacio por la modernidad. Su obra incluye estudios sobre escala, discursos acerca de la naturaleza, control de redes hídricas, contextos de post democracia todos anclados en denso análisis crítico sobre la globalización. Recientemente, ha publicado Liquid Power, libro en lo cual analiza el rol del controle de las redes hídricas en la producción del espacio español por el gobierno franquista. Esta entrevista ocurrió en inglés y debido a la presencia del Profesor Swyngedouw en la Conferencia "Knowledge / Culture / Ecologies" en Santiago de Chile, en noviembre de 2017, habiendo sido traducida por mí al portugués.

Palabras clave: Escala; Marxismo; Globalización; Movimientos Sociales.

César Martinez: Muito obrigado pela sua disposição. Sei que seu tempo no evento tem sido bem aproveitado e por conta disso sua agenda é justa. Existem atualmente poucas formas de acessar sua obra em Português, a maior parte é composta por resenhas de alguns dos seus livros mais importantes. Por isso, gostaria de partir pedindo que você relatasse um pouco da sua biografia, pois apesar de ter um extenso trabalho junto à geografia e à ecologia política, sua formação original é em Agronomia, não é mesmo?

Erik Swyngedouw: Sim! Eu nasci em 1956 em uma pequena vila da Bélgica Holandesa², com apenas algumas centenas de habitantes e em um contexto de agricultura familiar. Aí eu vivi por 6 anos, quando me mudei para a cidade local. Quanto eu tinha 18 anos, fui à Universidade de Lovain para estudar Engenharia Agrícola. Apesar do meu histórico, eu tinha essa ideia romântica de uma vida em comunidade produzida pela modernidade, pelas mudanças tecnológicas, pela organização, e isso foi o que me motivou a cursar Engenharia Agrícola e de Meio Ambiente. Em minha inocência à época, eu achava que a solução estava na tecnologia. Eu era envolvido com movimentos sociais, como o movimento anti-nuclear, e acreditava que eram as diferentes tecnologias e os diferentes entendimentos de ciência e tecnologia que poderiam salvar o mundo. Contudo, descobri depois muito rapidamente, quando ainda era adolescente e me envolvi com mobilizações políticas, por volta do final dos anos 1960 início dos 1970, que não eram a ciência e a tecnologia que conduziam o processo social e sim o capitalismo. Então, passei a me preocupar cada vez mais em entender as

${ }^{2}$ NT: Comunidade Flamenga 
geografias desiguais da modernização e as condições que elas produzem. E foi automaticamente com a descoberta d O Capital de Marx que comecei a ter alguns insights dos mecanismos que combinavam um desenvolvimento geográfico desigual, por um lado, com os abismos culturais e mentais associados a isso. Mas, ao mesmo tempo, oferecendo uma solução em potencial, uma revolução social. Assim, apesar de meus avanços no entendimento teórico das interpretações políticas de esquerda, apenas tive uma compreensão política das diferenças no processo de formação espacial a partir de tomar contato com autores como Henri Lefebvre e David Harvey, em particular. Isso abriu para mim a possibilidade de entender teoricamente a diversidade das paisagens interconectadas pelas configurações de poder sócio-espaciais desiguais. Basicamente, foi dessa forma que acabei me tornando geógrafo, pois acabei realizando meu doutorado com David Harvey. Eu queria explorar mais e fugir dessa solução tecnológica, principalmente através de uma perspectiva muito mais sociológica, política e ativista de compreender o mundo e, consequentemente, agir sobre o mundo. Com isso, começou a ficar cada vez mais claro para mim - e eu agradeço a David Harvey por isso - que teríamos que ter um projeto de emancipação social, um projeto geográfico de emancipação social. Um projeto político que não só fizesse uma distinção dos espaços, mas que desse conta de maneira profunda das condições histórico-geográficas, pelo qual pudéssemos entender que a transformação social deva ser particular a esses espaços. Por isso, a transformação deve ser um projeto político e geográfico. Dessa forma, precisamente em 1986, quando eu terminei meu doutorado, eu passava a maior parte do tempo tentando entender como a organização espacial era ativa na produção e reprodução do capitalismo e, por outro lado, como políticas de resistência também eram constituídas espacialmente, ainda que geograficamente diferenciadas. Mas foi nesse período, por volta dos anos 1980, que foi crescendo a crítica sobre a visão totalizante do marxismo sobre o mundo. Ela passou a ser atacada por dois flancos, basicamente. Primeiro, pelo pós-modernismo, pós-estruturalismo, que questiona as características brancas, masculinas, heterossexuais de produção do conhecimento. A desintegração das repúblicas socialistas pôs a teoria marxista sob crítica ideológica e eu não estava particularmente interessado na crítica pós-moderna à teoria marxista, pois acredito que se perdeu um pouco o foco sobre ao que a análise materialistahistórica-geográfica se referia. A outra crítica, que eu achava muito mais convincente, importante e interessante, foi a ecológica. Foi nos anos 1980 em que o movimento ecológico passou a centrar a condição ecológica na produção e reprodução do sistema capitalista e se passou a entender que as transformações do sistema capitalista eram cada vez mais articuladas 
ao sistema ecológico em que nós vivíamos. E eu realmente concordava que grande parte da crítica que se fazia à obra marxista era que ela havia ignorado as condições ecológicas e físicas. E isso é verdade! E nós, como marxistas, não vínhamos sendo muito bons em incorporar o poder do lugar e a ação das condições físicas às análises. Nos faltava considerar os jogos e ações de poder relacionados ao ambiente físico nas configurações de poder que promoviam o desenvolvimento do capitalismo. Assim, passei a estar mais interessado em como as relações sociais do capitalismo se articulavam com um processo ecológico para produzir uma paisagem sócio-ecológica desigual. Percebi como dinâmicas de dominação, resistência e transformação teriam que levar em conta em suas estratégias teóricas as condições ecológicas. Eu ainda mantenho a visão de Harvey sobre uma organização social conduzida geograficamente e me interesso em teorizar e entender sobre como o capitalismo urbano atua em conjunto com um desenvolvimento sócio-ecológico desigual. A isso me dediquei durante a década de 1990 e início da década de 2000.

CM: Minha primeira aproximação ao seu trabalho foi um artigo no qual Chris Collinge ${ }^{3}$ comenta sua teorização sobre o conceito de escala. De forma geral, você problematiza as noções binárias de global e local. Você poderia explica melhor essa crítica?

ES: Com certeza! Esse foi a certo ponto um assunto fundamental e eu ainda o considero muito importante. A centralidade do debate sobre a escala foi provocada pela época onde o grande tema era o processo de globalização, sobretudo nos anos 1990. Esse processo que destruía o local e incorporava tudo em uma forma de estrutura global. E eu achava isso muito problemático do ponto de vista teórico e também político, porque a globalização começou a ser reinterpretada como um processo de reescalonamento geográfico. Isso porque a ordem geográfica do século XX foi articulada no Estado-nação. A escala do Estado-nação foi a grande articuladora política e econômica dessas dinâmicas, de forma a coreografar e organizar os processos do que chamamos de "globalização". E isso ocorreu, conforme diria Marx, em um movimento duplo. Nunca um movimento singular, sempre um tensionando o outro e gerando essa configuração dialética. O que considerávamos estar ocorrendo era uma profunda transformação escalar das políticas econômicas neoliberais, o que presume a

\footnotetext{
${ }^{3}$ COLLINGE, C. The différance between society and space: Nested scales and the returns of spatial fetishism.

Environment and Planning D: Society and Space, 23(2), 189-206. 2005. https://doi.org/10.1068/d360t
} 
transnacionalização de certos processos e a desnacionalização, regionalização e descentralização de outros processos. Esse reescalonamento reativou relações sociais e econômicas de poder. Por exemplo, nesse tempo eu estive muito interessado na regulação da relação com o capitalismo. No caso da Europa e de muitos outros lugares, a relação com o capitalismo se tornou regulada pela escala do estado-nação. Os grandes compromissos com o capitalismo eram firmados e regulados sob a escala nacional. $\mathrm{O}$ que começou a ocorrer em meados da década de 1970, e que continuamos a ver nos anos 1980 e 1990 foi a transnacionalização dessas relações capitalistas. Essas relações transnacionais enfraqueceram o papel do Estado na regulação do capitalismo. A globalização passou a ser o processo pelo qual as negociações passaram a se situar à escala local. Nesse sentido, venho tentando entender a globalização em um movimento duplo no qual tanto transnacionaliza como subnacionaliza, atua localmente. O processo de reescalonamento não foi socialmente neutro, pois novas escalas geográficas passaram a se constituir. Clássico exemplo: a União Europeia, onde de fato a institucionalização política e econômica assume uma escala supranacional.

CM: Esses processos têm impacto na fusão de diferentes escalas?

ES: Sim. A sobreposição de escalas geográficas tem muita implicância na forma como atuam os movimentos sociais, por exemplo. O que observávamos na década de 1960 e 1970 era que o "inimigo", ou seja, o espaço que tínhamos que ocupar era o Estado-nação. O que a maior parte dos movimentos políticos nessa época buscava era controlar o poder estatal. Hoje em dia, não é suficiente articular uma estratégia de poder apenas visando o Estado. Um bom exemplo dessa impossibilidade, dessa incapacidade em ocupar o Estado buscando a transformação social, é o que acontece na Grécia. Os gregos tiveram uma mudança política extraordinária, a esquerda triunfou. Contudo, devido ao Estado em um arranjo multiescalar, eles não obtiveram sucesso. Inevitavelmente lançou-se a dúvida sobre como movimentos oposicionistas podem lutar simultaneamente contra uma variedade de escalas geográficas. Ainda lutamos para responder à questão de como fazê-lo. A incapacidade de agir em diferentes escalas fez com que ativistas e intelectuais conduzissem seus esforços à escala local. Porém, essa escala local está entrelaçada em uma complexa coreografia que sobrepõe diversas outras escalas. O grande problema é que não sabemos muito bem como resolver isso. O que eu sugiro é que os movimentos políticos devem ter em conta essa complexidade da 
estrutura escalar, pois no âmbito do capitalismo, o poder está estruturado geograficamente. Por isso, ressalto a centralidade do espaço nas geometrias do poder capitalista.

CM: Eu lembro do seu argumento sobre esta dependência da escala nacional em sua última ida ao Brasil, em 2014. Na ocasião, tratava-se de discutir os temas relacionados ao controle da água, politizando o debate sobre as redes hídricas. Você considera que o seu trabalho, nesse sentido, questiona as barreiras entre uma geografia física e uma geografia social?

ES: Deixe-me separar isso em duas partes. Primeiramente, temos a separação entre o físico e o humano. Na outra, é necessário aprofundar "o político"”. Muitos de nós compreendíamos que o social deveria levar em conta o não-humano, o físico. Isso ainda como algo que sofremos por esse legado positivista que separava as ciências sociais das naturais. Isso ocorre até mesmo na nossa disciplina, na Geografia, que deveria ser supostamente a disciplina que articula ambas dimensões. Na década de 1950, por exemplo, tínhamos geógrafos sociais econômicos, urbanos, etc. - e geógrafos físicos - que se preocupavam com os rios, as paisagens, etc. E pensávamos que a geografia era o impacto de uma coisa na outra. O impacto do mundo físico no mundo social, já supondo que eram naturalmente separados. Então se entendeu que isso era teoricamente problemático. Alguns de nós passaram a procurar formulações teóricas onde o não-humano fosse parte constituinte do entendimento do mundo, sem discernir esse mundo como particularmente físico ou humano. E passou a ficar mais claro que teríamos que encontrar formas de compreender esse arranjo natureza-sociedade de maneira que sobrepassasse essa separação. Isso é sobre o que o meu trabalho trata, fundamentalmente. Eu uso a água como um artefato que me ajuda a escavar a circulação do poder. E venho percebendo que não é possível entender sem considerar ambos aspectos, físicos e humanos. Se eu venho tendo sucesso em fazê-lo, aí já é outra história (risos). Essa vem sendo a tentativa. Consequentemente, buscar argumentar e demonstrar de que poder político, poder econômico e poder social são articulados particularmente através do momento em que o físico e o social são combinados. Quando você considera o espaço físico e social ao mesmo tempo, você percebe o quanto ele estrutura relações sociais desiguais.

CM: Isso seria o território?

${ }^{4}$ N.T.: The political 
ES: Exato! Estrutura o território e estrutura as desigualdades em diversas relações de poder nesse mesmo território. As relações sócio-políticas e sócio-físicas estão contextualizadas nesses fluxos que se estruturam. Assim, acredito que tenhamos tido sucesso em demonstrar o quanto relações ecológicas estão associadas em arranjos de poder desiguais. Como consequência, temos que a fusão entre o social e o físico é relevante politicamente. Agora deixe-me falar sobre "o político". A questão era de que havia um erro. E quando digo um erro, quero dizer que não foi apenas meu erro, mas de nós todos. Se nós voltássemos agora, veríamos que o motivo pelo qual eu e outros nos interessávamos pela análise históricomaterialista era a premissa de que fazendo este tipo de análise impactaríamos na promoção de um pensamento político crítico e emancipatório. Dessa forma, pensávamos que uma boa análise sócio-física nos daria a vantagem para transformar o sistema a um modo mais igualitário, democrático e sustentável. Basicamente, os mesmos argumentos que as feministas utilizavam, que os pós-estruturalistas também utilizavam. Ou seja, praticamente todos envolvidos na teoria crítica argumentavam, explícita ou implicitamente, que a teoria social era importante politicamente falando.

CM: Poderíamos ampliar essa crítica a premissas contemporâneas de que a técnica se sobrepõe ao político? A ideia de smart cities, muito em voga na gestão urbana, por exemplo.

ES: Em boa parte, sim. Eu tenho escrito extensivamente sobre isso, fundamentado pelo fato de que o ambiente urbano é uma confusão sócio-física-cultural, o que eu concordo. Contudo, surge essa ideia da smart city como a grande solução, a panaceia dos problemas urbanos. Assim, comecei a pensar sobre algo que muitos de nós fomos nos esquecendo ou ignorando: “o político". Nós podemos demonstrar que configurações sócio-ecológicas, como a que vemos com a água ou com a urbanização por exemplo, materializam as relações desiguais de poder. Então, eu comecei a pensar na distinção entre "políticas" e "o político". As políticas vêm associadas às instituições concretas da sociedade: às decisões, aos arranjos de governo, aos planos e projetos. Pode-se facilmente mapear as decisões tomadas nas políticas, concordemos ou não com elas. O que não podemos prever ou controlar é o que chamamos de emergência do político. Enquanto as políticas são algo que se pode ver, você não consegue ver o político. O político é o conceito que se levanta para enfrentar a ideia de que a sociedade não existe de maneira coesa, mostrando que a mesma é altamente variável e heterogênea. A existência desse político não pode ser vista, mas se manifesta ocasionalmente como forma de 
interrupção de certos sistemas. Esse é o momento em que vemos um grupo de pessoas levantaram-se e dizerem: eu não aguento mais isso! Exemplos disso são o movimento de estudantes no Chile em 2011, os movimentos de ocupação, a primavera árabe. Desde 2011, temos uma proliferação desses levantes.

CM: Podemos assumir que esses levantes são buscas por encontrar brechas no sistema predito pelas políticas?

ES: Você pode chama-lo assim se você quiser. Existe essa ordem prescrita pelo sistema político e ocasionalmente algo erupciona provocando mudanças, maiores ou menores, na ordem institucional. Isso é o que eu chamaria de momento de possibilidade do político. É o que chamamos em política da ocupação de uma fronteira, produzindo uma nova espacialidade. Isso porque nunca é uma ocupação neutra, mas sempre uma tentativa de transformar a ordem institucional. Geralmente falham, mas em algumas vezes há êxito. Não estou falando aqui daquele slogan da década de 1960 "política em toda parte" - no banheiro, na rua, no trabalho - mas do imprevisível. A questão é estudar o político como essa interrupção do espaço público, quando pessoas se unem e fazem um levante sobre novas formas de pensar a ecologia, a cidade, as políticas. E essa é minha grande crítica aos meus colegas ambientalistas. A maior parte deles está focada em um evento particular: a perda de terras de uma comunidade indígena, uma represa, uma mina. E isso importa! Meu ponto não é que essas coisas não sejam importantes, mas que não são o suficiente. É uma forma de resistência social, o que é importante, mas pode ter um efeito despolitizante. O politizante acontece quando o evento extrapola para uma demanda universal. Deixe-me dar um exemplo. Em 2013, na Turquia, na praça Taksim Gezi, centenas de milhares de pessoas uniram-se e mobilizaram-se - intelectuais, artistas, trabalhadores - a partir do estopim de um anúncio de corte das árvores para construção de um shopping. Clássico arranjo sócio-ecológico: "nós não queremos que essas árvores sejam cortadas e não queremos a construção desse shopping”. Clássico exemplo de movimento social, partindo de um evento muito singular - algumas árvores e a construção de um prédio - e é rapidamente universalizado transformando-se por uma demanda por democracia, por democratização. Então, começamos a nos dar conta que não era pelas árvores, era pela democracia. Você precisa entender isso quando trabalha com situações ecológicas. Isso é o que eu chamo de "movimento", uma preocupação social ou uma 
preocupação ecológica com importância política. Meu argumento chave para os meus amigos ambientalistas é que deixem de falar sobre uma condição sócio-ecológica específica e veja como essa condição específica se universaliza para uma demanda democrática mais ampla, deixando emergir o político. É o que venho tentando dizer nas minhas falas. E aí recebo muitas críticas por isso, mas defendo a ideia de que não é que A não seja importante e sim que é preciso pensar em A e B juntos.

CM: Não quero tomar muito mais do seu tempo. Por isso, gostaria de deixar espaço para que você comentasse algo sobre sua produção recente, seu último livro.

ES: Meu último livro se chama "Liquid Power"5 e é sobre a Espanha. Ele se dedica precisamente à história sócio-ecológica da Espanha no século XX. É uma história sobre a água, esse é o tema do livro, o poder líquido. O que eu quero demonstrar narrando essa história sócio-ecológica é que a Espanha foi atormentada por guerras civis, fascismo, uma história atormentada, muito sofrimento. A Espanha teve muitas disputas de poder e muitas mudanças políticas ao longo do século. O que eu quero manifestar com o livro é que a condição física e ecológica teve um papel fundamental na estruturação e na reestruturação dessas mudanças e das configurações de poder no país. Meu argumento central é que não é possível entender a história social da Espanha sem entender o social e o ambiental juntos. Eu não conseguia entender como o fascismo, mais especificamente o franquismo, conseguiu ficar tanto tempo no poder na Espanha. Foram quase 40 anos, é muito tempo! O que eu busco demonstrar é como Franco põe atenção mais à condição sócio-física que à condição social especificamente. Ele utiliza a água e o controle sobre as redes hídricas para estruturar o território.

CM: Sobre as hidromodernidades, no Brasil, tivemos o caso da transposição do rio São Francisco e como isso foi uma metáfora política importante do governo Lula para marcar a integração da região nordeste ao mapa da política brasileira.

\footnotetext{
${ }^{5}$ SWYNGEDOUW, Erik. Liquid power: Contested hydro-modernities in twentieth-century Spain. Estados Unidos: MIT Press, 2015.
} 
ES: Com certeza! Esse é um excelente exemplo do reescalonamento das políticas, pois mostra como a escala é produzida e como ela altera as geometrias do poder.

CM: E ainda nesse caso, como isso se transforma em capital político.

Exatamente! E isso é fantástico, porque é precisamente o que tento demonstrar no livro sobre a Espanha. Exemplos podem ser encontrados em qualquer país, mas o Brasil seria um exemplo sensacional para observar isso. Há um novo livro saindo no próximo ano e ele se dedica ao político. Com ele, eu tento fazer duas coisas. Primeiramente, um diagnóstico do processo de despolitização, quando nos últimos dez ou quinze anos a maior parte das pessoas perdeu a confiança nas políticas, muitos desistiram. A maior parte porque não acredita nas instituições políticas, que elas podem fazer alguma diferença. Isso é a despolitização, que vem associada a uma busca cada vez maior pelo populismo. Eu faço esse diagnóstico teoricamente, mas buscando demonstrar empiricamente como essa condição despolitizante - a que eu chamo de condição pós-democrática - muda conforme também mudam as políticas ambientais. O segundo tópico do livro é mostrar possíveis momentos de livre politização, onde eu observo em particular a proliferação do que chamo de insurgências urbanas desde 2011: Occupy, primavera árabe, estudantes do Chile, entre outros. O interessante é que apesar da heterogeneidade geográfica desses levantes, eles estão acontecendo em toda parte. Embora eles sejam disparados por diferentes motivos - no Chile foi a educação...

CM: No caso do Brasil em junho de 2013, foi o preço da passagem no transporte público

ES: De novo, um ótimo exemplo. O preço da passagem, algo pequeno, de repente explode em demandas de todo tipo. Passam a questionar o modelo antidemocrático de certos governos. Então, nesse novo livro eu ponho atenção a esses sinais de politização.

CM: Já há um título?

Sim, "The Promises of the Political"! 
CM: Bem, a minha promessa foi cumprir o tempo previsto para essa entrevista. Assim, lhe agradeço imensamente pela disponibilidade.

ES: O prazer foi meu!

Recebido em 09 de março de 2018.

Aceito em 30 de março de 2018. 